\title{
Coordenadoria de Relações Internacionais da Cidade do Rio de Janeiro e os dois níveis da análise paradiplomática
}

\author{
International Relations Department of Rio de Janeiro's City Hall and the two levels \\ of paradiplomatic analysis
}

Leonardo Mèrcher ${ }^{1}$

\section{RESUMO}

O presente artigo busca identificar a existência de uma preocupação constante da Cidade do Rio de Janeiro com sua participação internacional que, consequentemente, exige uma organização de suas práticas internacionais. Essa organização $e$ constância da ação internacional resultariam em uma paradiplomacia - diplomacia paralela ao governo nacional e institucionalizada - por meio da Coordenadoria de Relações Internacionais, fundada em 1987 e em funcionamento até o presente. Utiliza-se da análise de conteúdo de atas, tratados e outros documentos em dois níveis - o operacional local e o internacional - em uma interpretação qualitativa, advinda de perspectivas construtivistas das Relações Internacionais. Os resultados obtidos demonstram que a cidade do Rio de Janeiro possui uma preocupação e ação constante diante de assuntos internacionais, bem como a institucionalização de sua paradiplomacia nos últimos anos por meio da Coordenadoria de Relações Internacionais.

Palavras-chave: Rio de Janeiro; cidade global; paradiplomacia.

\begin{abstract}
This article seeks to identify that there is a constant concern of the Rio de Janeiro City with its international participation thus requiring an organization of their international practice. This organization and consistency of international action would result in a paradiplomacy - parallel and institutionalized diplomacy of national governments - through the Coordination of International Relations founded in 1987 and running until the present. This research is supported by a content analysis of treaties and other documents on two levels: the local operational and international - in a qualitative interpretation from constructivist perspectives of International Relations. The results show that Rio has a constant concern and action on international issues as well as on institutionalizing its paradiplomacy in recent years by the International Relations Department of Rio de Janeiro's City Hall.
\end{abstract}

Keywords: Rio de Janeiro; global city; paradiplomacy.

\footnotetext{
${ }^{1}$ Doutorando em Ciência Política pela Universidade Federal do Paraná. Professor de Relações Internacionais do Centro Universitário Internacional - UNINTER, Curitiba, Brasil.
} 


\section{Introdução}

Ao longo da história as cidades demonstraram interações em diversos níveis de análise. A presença política de cidades nas relações entre povos e nações, bem como na orientação de interesses comuns, é vista desde a Idade Antiga nas chamadas Cidades-Estados. Entretanto, na contemporaneidade as cidades submeteram-se à formação do Estado-Nação e aos seus governos centrais tornando-se governos subnacionais. A subnacionalidade, contudo, não as renegou às atividades exclusivas do espaço doméstico - ou infranacional - permitindo que diversas vezes os governantes subnacionais atuassem no cenário internacional em defesa dos interesses de suas comunidades. Dessa forma, o século XX tornou-se testemunha de uma retomada da atuação subnacional nas relações internacionais que consolida-se no século XXI.

Enquanto que no ato coletivo das últimas décadas as cidades criaram redes e outras instituições voltadas à cooperação internacional, à transferência de políticas públicas e à defesa de seu lugar em meio às dinâmicas internacionais, o crescimento de determinados centros urbanos - cidades e suas regiões metropolitanas - trouxe consigo um ganho político aos seus governos, tanto como palco das dinâmicas internacionais, como experiência e demanda para gerir assuntos externos. Os grandes centros urbanos no mundo não se mantiveram apenas como palco de dinâmicas financeiras, políticas e culturais, mas ampliaram sua participação em diversas agendas internacionais, exigindo espaço nas tomadas de decisões (SASSEN, 2010).

Nesse sentido, pode-se identificar ao menos três campos de ação das cidades nas relações internacionais contemporâneas: suas interações com as conferências e instituições do Sistema ONU; suas próprias redes, como as Mercocidades, FLACMA e CGLU; e as dinâmicas autônomas, como as relações bilaterais e outras iniciativas medidas, por exemplo, pela A. T. Kearney Global Management Consultants de Chicago, a Globalization and World Cities Research Network do Departamento de Geografia da Universidade de Loughborough (GaWC) e The Global Cities Institut da Universidade de Toronto. No nível interno pode-se analisar a ação internacional das cidades ao identificar no governo local as suas 
ferramentas e instituições envolvidas com o tema que, no caso da cidade do Rio de Janeiro (Rio), identifica-se a Coordenadoria de Relações Internacionais (CRI).

Caso haja uma busca para identificar a existência de uma paradiplomacia diplomacia paralela da cidade de forma planejada em relação ao seu governo nacional e, muitas vezes, institucionalizada, é na CRI que pode-se encontrar a resposta ao estudar a cidade do Rio. Por meio de suas relações com organizações internacionais do Sistema ONU e redes de cidades, como o Banco Mundial e as Mercocidades, respectivamente, ou por meio de ações próprias, como candidaturas a eventos esportivos e transferência de políticas públicas, o Rio concentra boa parte de sua gestão municipal internacional na CRI, composta por um corpo especializado na agenda de assuntos internacionais da cidade. Criada em 1987, a CRI sofreu alterações pontuais, sobretudo no que diz respeito à ampliação de responsabilidades e funções, instrumentalizando a paradiplomacia dos governos municipais que se sucederam no poder local.

\section{Cidades Globais: uma breve explanação sobre a natureza do Rio}

Dentre tantas cidades que atuam no cenário internacional destacam-se as cidades globais. Essas, como um conceito definido por Saskia Sassen (1991), sendo um desdobramento do conceito de cidades mundiais de John Friedmann (1986), teriam um peso maior diante das dinâmicas internacionais e transnacionais contemporâneas do que as demais devido ao seu porte urbano, a concentração e contribuição econômica à região, seu alto índice populacional e também poder de barganha diante de outros agentes externos. Pesquisas de origens diversas como as apresentadas pela A. T. Kearney (2008; 2010; 2012; 2014), GaWC (1999; 2015) e The Global Cities Institut (2015) definem quais seriam essas grandes capitais do mundo contemporâneo e indicam diversos nichos de relevância diante de dinâmicas internacionais.

Muitos estudos e considerações sobre cidades globais, por exemplo, prendem-se no fator econômico e de crescimento populacional, como as da GaWC e The Global Cities Institut, mas outras, como a própria A. T. Kearney em seus indexadores, indicam áreas diversas relevantes para o interesse de pesquisas em 
novas agendas. A cultura, por exemplo, é indicada não apenas como um fator ligado ao desenvolvimento econômico, mas também à própria identidade do agente e seu comportamento. 0 cenário internacional para as cidades, por essas estarem livres de questões de soberania (ROSENAU, 1990, p. 36), acaba tornandose menos competitivo e mais cooperativo. Juntamente com os processos de globalização - sistema financeiro, desenvolvimento tecnológico e de transportes, as distâncias geográficas passam a ser superadas e a aproximação de seus habitantes e gestores torna-se uma constante.

Não é difícil de identificar transferências de políticas públicas entre cidades globais, como nas redes de cidades. Contudo, as mesmas não se limitam à cooperação. Além de agentes elas tornam-se índices para se compreender as Relações Internacionais (The Global Cities Institute, 2015; A.T. Kearney, 2014; GaWC, 2015), sobretudo ao concentrar em seus espaços a maior parte da população global, bem como da gestão de riquezas, encontros e debates políticos entre Chefes de Estado e ao sediar organismos internacionais atrelados a regimes. A relação, por exemplo, entre gestão municipal e instituições e conferências internacionais de Estados acaba por aproximar as cidades das dinâmicas internacionais. Cabe ressaltar, portanto, que as cidades não vão às relações internacionais, mas essas transpassam níveis estabelecidos pelos Estados. $\mathrm{Na}$ ótica de alguns teóricos, como Alexander Wendt (1999) ou Saskia Sassen (2010), as Relações Internacionais não se dão apenas no nível externo às fronteiras estatais, mas sim em toda parte. Dessa forma, as cidades acabam por poder atuar no cenário internacional, tanto como tradicional palco, quanto como agentes ao produzirem metas e atividades que as inserem em ganhos à população local.

\section{A Coordenadoria de Relações Internacionais}

A Coordenadoria de Relações Internacionais e Cerimonial da Cidade do Rio de Janeiro (CRI) foi estabelecida em 1987 como órgão municipal responsável por assessorar o poder executivo municipal - Gabinete do Prefeito. Dentre suas funções destacam-se a elaboração e execução de políticas públicas municipais relativas à cooperação e atuação internacionais. Mas nem sempre foi assim. Antes 
de sua criação, em 1975, foi criado o Cerimonial, cuja função era o de assistir diretamente o Prefeito no que dizia respeito às práticas de cortesia, recepção, celebrações e outros eventos que exigiam comportamento protocolar da prefeitura. O Cerimonial, como órgão imediatamente ligado ao Gabinete do Prefeito, perdurou em sua definição até 1986, quando, por meio do Decreto no 5.752 de 08 de abril de 1986, foi criada a Assessoria Internacional que o substituiu.

A Assessoria Internacional assumiu as competências e atribuições do antigo Cerimonial até ser extinta no ano seguinte, dando lugar à Coordenadoria de Relações Internacionais e do Cerimonial (CRI) pelo Decreto no 6.917 de 02 de setembro de 1987. Como órgão assessor mantém-se ligado ao Gabinete do Prefeito do Rio. A cidade tornou-se, então, "o primeiro município do Brasil a ter uma estrutura exclusivamente dedicada ao tema" (CRI, 2015). Em sua estrutura inicial foi coordenada por um diplomata de carreira, bem como auxiliada por dois assessores e quatro assistentes. 0 primeiro coordenador foi o Embaixador Claudio Garcia de Souza, durante o governo municipal de Roberto Saturnino Braga (19861988), então filiado ao Partido Democrático Trabalhista (PDT).

Desde sua criação, a CRI tem sido coordenada por diplomatas de carreira. Nos últimos anos sua estrutura foi organizada da seguinte forma: cargo de Coordenador de Relações Internacionais, seguido pelo Coordenador Adjunto de Relações Internacionais, Chefe de Gabinete e as Gerências. As Gerências são compostas pela: Gerência de Cooperação Bilateral, Gerência de Cooperação Multilateral, Gerência de Relações Institucionais, Gerência de Missões e Eventos, Gerência de Planejamento e Gestão, e a Gerência da Equipe Administrativa. Atualmente o seu Coordenador de Relações Internacionais é o Ministro Laudemar Aguiar (2013), juntamente com seu Coordenador Adjunto Bruno Neele e a Chefe de Gabinete Adriana Zonis (CRI, 2015).

A atual coordenação iniciou seus trabalhos em 2013 "num momento-chave para a Cidade do Rio de Janeiro, de grande visibilidade internacional" (CRI, 2015) devido: à Copa das Confederações (2013), Jornada Mundial da Juventude (2013), Copa do Mundo (2014), celebração do aniversário de 450 anos da Cidade (2015), Olimpíada de Verão (2016), e a Paralimpíada de Verão (2016). Além desses 
eventos o Rio sediou diversos outros de visibilidade internacional, como a ECO92 (1992), Pan-Americano (2007), V Fórum Urbano Mundial (2010) e o Rio+20

(2012). Em todos esses eventos a CRI manteve participação dada sua natureza institucional.

Além de contribuir na captação e realização de eventos com visibilidade internacional, a CRI "age como facilitadora de projetos de cunho internacional entre a Prefeitura do Rio e as secretarias municipais, órgãos estaduais e federais, identificando oportunidades e acompanhando projetos internacionais de cooperação nas mais diversas áreas" (CRI, 2015), sendo a "principal interlocutora da prefeitura com repartições consulares e missões diplomáticas, entre outras entidades internacionais de cunho regional e multilateral, bem como com as redes internacionais de cidades" (CRI, 2015). Em seu decreto de criação ficou estabelecido que suas funções seriam:

\begin{abstract}
assistir ao Prefeito em assuntos internacionais, interestaduais e intermunicipais, de natureza econômica, financeira, cultural, educacional e tecnológica; se relacionar com organismos nacionais e internacionais, dos quais seja membro o Governo Municipal; elaborar estudos e efetuar pesquisas nas esferas política, econômica, social, cultural e tecnológica, sobre as relações internacionais e nacionais em que o Município se veja envolvido; participar de reuniões, congressos, simpósios e certames nacionais e internacionais, levados a efeito no Brasil e no exterior, quando o Prefeito assim autorizá-lo; efetuar contato com vistas à obtenção de doações e financiamentos internacionais para obras e realizações previstas nos planos de governo; executar, no âmbito municipal, as atividades relativas ao cerimonial Público; elaborar a correspondência do Prefeito com órgãos diplomáticos, Câmaras de Comércio e outras entidades de representação estrangeira; assistir o Prefeito, representá-lo e colaborar com outros órgãos da Prefeitura em solenidades, recepção e festividades; supervisionar a distribuição de convites para solenidades; e organizar, em cooperação com os cerimoniais da Presidência da República, do Ministério das Relações Exteriores e do Governo do Estado do Rio de Janeiro, as solenidades cívicas realizadas no Município do Rio de Janeiro (CRI, 2015).
\end{abstract}

Reforça-se aqui sua função de coordenação das ações exteriores do Rio, bem como seu corpo especializado em relações internacionais. Fruto de sua ação, a cidade participa em diversas instituições internacionais. Segundo a CRI, o Rio está vinculado: ao C40CITIES (Grupo C40 de Grandes Cidades para Liderança do Clima, originalmente C20); à União de Cidades Capitais Ibero-Americanas (UCCI); à União das Cidades Capitais de Língua Portuguesa (UCCLA); às Cidades e Governos Locais 
Unidos (CGLU); à Associação Mundial das Grandes Metrópoles (Metropolis); à Federação Latino-Americana de Cidades, Municípios e Associações de Governos Locais (FLACMA); à União Mundial de Cidades Olímpicas (WUOC); aos Governos Locais pela Sustentabilidade (ICLEI), à Waze Connected Citzens (W10); ao Projeto AL-LAS; às Mercocidades; aos Prefeitos pela Paz (Mayors for Peace); ao Fórum Mundial para Cultura (World Cities Culture Forum); e pontualmente às fundações Rockefeller e Konrad Adenauer, além de organizações do sistema ONU, como a Habitat, UNICEF, PNUD, UNISDR e UNESCO.

Atuando como membro efetivo, convidado ou observador, o Rio mostra-se presente nas principais instituições internacionais de cidades, como a CGLU - ao nível global - e às Mercocidades - ao nível regional. Localizada no Palácio da Cidade, em Botafogo, a CRI também formula e executa a política de Relações Internacionais da cidade, como no caso das transferências de políticas públicas, cooperação, captação de recursos, acordos de irmanação e participação nos eventos e instituições mencionados. A cidade e sua CRI, contudo, fazem parte de um contexto de mobilização internacional coletiva, no qual diversos outros governos subnacionais sustentam atividades intergovernamentais, como no caso dos acordos que definem cidades-irmãs e cidades-parceiras, fortalecendo laços de identidade, história e economia, bem como favorecendo a transferência de políticas públicas e as demais atividades internacionais bilaterais.

O Rio atualmente possui 32 cidades-irmãs e 5 cidades parceiras. Das cidades-irmãs, duas são brasileiras - São Borja (RS) e Bagé (RS) - e trinta internacionais: Barcelona e Santa Cruz de Tenerife (Espanha); Buenos Aires (Argentina); Seul (Coréia do Sul); San José (Costa Rica); Atlanta e Newark (Estados Unidos da América); Nantes e Saint-Tropez (França); Jerusalém (Israel); Ramallah (Palestina); Kobe (Japão); Arganil, Cabeceiras de Basto, Coimbra, Espinho, Guimarães, Olhão, Santo Tirso e Vila Nova de Gaia (Portugal); Liverpool (Reino Unido); Bucareste (Romênia); Rufisque (Senegal); Túnis (Tunísia); Istambul (Turquia); Kiev (Ucrânia); Caracas (Venezuela); Casablanca (Marrocos); Colônia (Alemanha); e Luanda (Angola). Já as cinco cidades parceiras são: Natal e Salvador (Brasil), Oklahoma e Miami Beach (Estados Unidos da América), e Vancouver (Canadá). 
Essas parcerias e acordos intermunicipais possibilitam um maior diálogo e ação conjunta internacional, sobretudo por meio de trocas de informação, transferência de políticas públicas e de gestão. As redes horizontais de cidades, como as Mercocidades e a CGLU, reforçam os vínculos entre esses agentes que passam a construir dinâmicas próprias no cenário internacional. Desde o princípio da subsidiariedade - possibilidade dos governos subnacionais terem autonomia, inclusive internacional, para superar desafios em seus níveis locais - até a formulação de uma paradiplomacia - diplomacia paralela do governo subnacional em relação ao seu governo nacional - a cidade do Rio se põe como um agente ativo. Segundo a CRI, a cidade possui relações de cooperação bilateral e multilateral, além das institucionais.

A Gerência de Cooperação Multilateral da CRI cuida da atuação da cidade e de sua agenda política diante das redes e instituições anteriormente mencionadas, como a CGLU. Já a Gerência de Cooperação Bilateral da CRI é responsável pelas relações diretas com outros governos subnacionais e Estados. Dentre suas prioridades encontram-se "identificar e promover o intercâmbio de políticas públicas internacionais bem sucedidas e promover o intercâmbio entre a administração municipal e cidades no exterior" (CRI, 2015). Seus projetos englobam áreas que perpassam desde procedimentos técnicos, culturais e de educação até as áreas empresarial e tecnológica. Elas se materializam por meio de acordos de cooperação diretos, irmanação e auxílio às missões internacionais tanto no envio de delegações, como em sua recepção. A cidade utiliza-se também da vantagem de possuir em seu espaço diversas representações diplomáticas, como consulados, para ampliar suas relações bilaterais com os demais agentes internacionais.

Na Gerência de Relações Institucionais e nas demais, a CRI mantém relações com cidades e outras instituições nacionais, como o Fórum Nacional de Secretários e Gestores Municipais de Relações Internacionais (FONARI), além de manter em funcionamento seu corpo institucional. Assim, desde sua criação em 1987 até os dias de hoje, a CRI ampliou sua estrutura gerencial e de apoio às ações internacionais do Rio. Para além do cerimonial, alcançando conquistas como o 
empréstimo de US\$ 1,9 bilhão de dólares em 2010 pelo Banco Mundial ${ }^{2}$ e o reconhecimento como um dos 17 Patrimônios Mundiais da Humanidade no Brasil pela UNESCO em 2012, foi a primeira cidade a receber o título no mundo na categoria Paisagem Cultural. Dessa forma, a CRI desenvolve-se diante das agendas propostas pelos seus gestores políticos - os prefeitos e seus secretários.

Desde a criação da CRI e atuação do Rio nos últimos anos nas relações internacionais, diversas mudanças ocorreram diante das relações partidárias da cidade. Governos municipal, estadual e federal perpassaram por períodos partidários distintos, tendo momentos de maior ou menor diálogo entre si. A CRI foi estabelecida em 1987, durante o governo municipal de Roberto Saturnino Braga do PDT (1986-1988). O PDT manteve-se no governo do Rio até 31 de dezembro de 1992, com os prefeitos Jó Antônio Rezende (1988) e Marcello Alencar (1989-1992). Em 1993 assume o prefeito César Maia em seu primeiro mandato (1993-1996) pelo PMDB (até 1995) e PFL (1995-1996). Em 1997 é eleito para prefeito do Rio Luiz Paulo Conde, ex-Secretário de Urbanismo durante o governo de César Maia, pelo PFL (1997-2000). Em 2001 César Maia retorna ao cargo de prefeito eleito pelo PTB, refiliando-se (sic) em 2002 ao PFL, que se transforma em DEM. No DEM, César Maia reelege-se em 2005, fechando seu terceiro mandato em 2008. Em 2009 assume Eduardo Paes do PMDB, também ex-secretário do governo de César Maia, mas sem apoio do mesmo na candidatura. Eduardo Paes se reelege em 2013 e permanecerá no cargo até o fim de 2016.

Em relação ao governo do Estado do Rio de Janeiro (RJ), a fundação da CRI ocorre durante o governo de Moreira Franco (1987-1991) do PMDB, seguido por Leonel Brizola (1991-1994) e Nilo Batista (1995), ambos do PDT. Marcello Alencar (1995-1999) do PSDB elege-se governador, seguido por Anthony Garotinho (19992002), inicialmente pelo PDT e, em 2000, filiando-se ao PSB. Benedita da Silva do PT, como vice-governadora do Estado do Rio de Janeiro, assume seu cargo após a renúncia de Garotinho em 2002. Seu governo foi sucedido, em 2003, pela eleição da esposa do ex-governador Anthony Garotinho, Rosinha Garotinho, que assume o

2 "Prefeitura e Banco Mundial formalizam empréstimo de $R \$ 1,9$ bilhão para investimentos na cidade. Dinheiro será utilizado para amortizar em até 25\% a dívida da Prefeitura com a União". Prefeitura do Rio de Janeiro. Disponível em <http://www.rio.rj.gov.br/web/guest/exibeconteudo?article$\underline{\mathrm{id}=1057895}>$. Acessado em 17/03/2015. 
governo do Estado (2003-2007), saindo do PSB, em 2004, para o PMDB. Após Rosinha Garotinho, o candidato Sérgio Cabral do PMDB torna-se governador (2007-2014), seguido pelo atual governador Luiz Fernando de Souza Pezão, também do PMDB (2014-2019).

Já no governo federal, em 1987 encontrava-se no poder o Presidente José Sarney do PMDB (1985-1990), seguido por Fernando Collor de Mello do PRN (1990-1992), Itamar Franco do PRN (1992-1995), Fernando Henrique Cardoso do PSDB (1995-2003), Luiz Inácio Lula da Silva (2003-2011) e a atual Presidente Dilma Rousseff (2011-2019), ambos do PT. Dentro desse cenário apresentado a alternância partidária teve relação direta com o apoio que o município recebeu das demais instâncias nacionais. A CRI nasceu em uma situação política de relações partidárias mais fáceis entre os governos municipal, estadual e federal. Durante o governo de Fernando Collor, iniciam-se os primeiros desentendimentos da cidade com o governo federal dos anos 1990, que se estabiliza com a eleição de César Maia, juntamente com a de Marcello Alencar (PSDB) no governo estadual e Fernando Henrique Cardoso (PSDB) no governo federal.

Contudo, esse breve momento de entendimentos (1995-1999) foi rompido pelos desentendimentos entre César Maia na prefeitura e Anthony Garotinho e seus sucessores no governo estadual. De 1999 até 2009 as relações entre prefeitura, governo estadual e governo federal são deterioradas por fortes oposições, reestabelecendo-se apenas com Eduardo Paes (PMDB) em 2009, encontrando apoio partidário do governo estadual de Sérgio Cabral (PMDB) em situação com o governo federal do PT. Abaixo segue uma breve relação figurativa das alternâncias partidárias do período: 


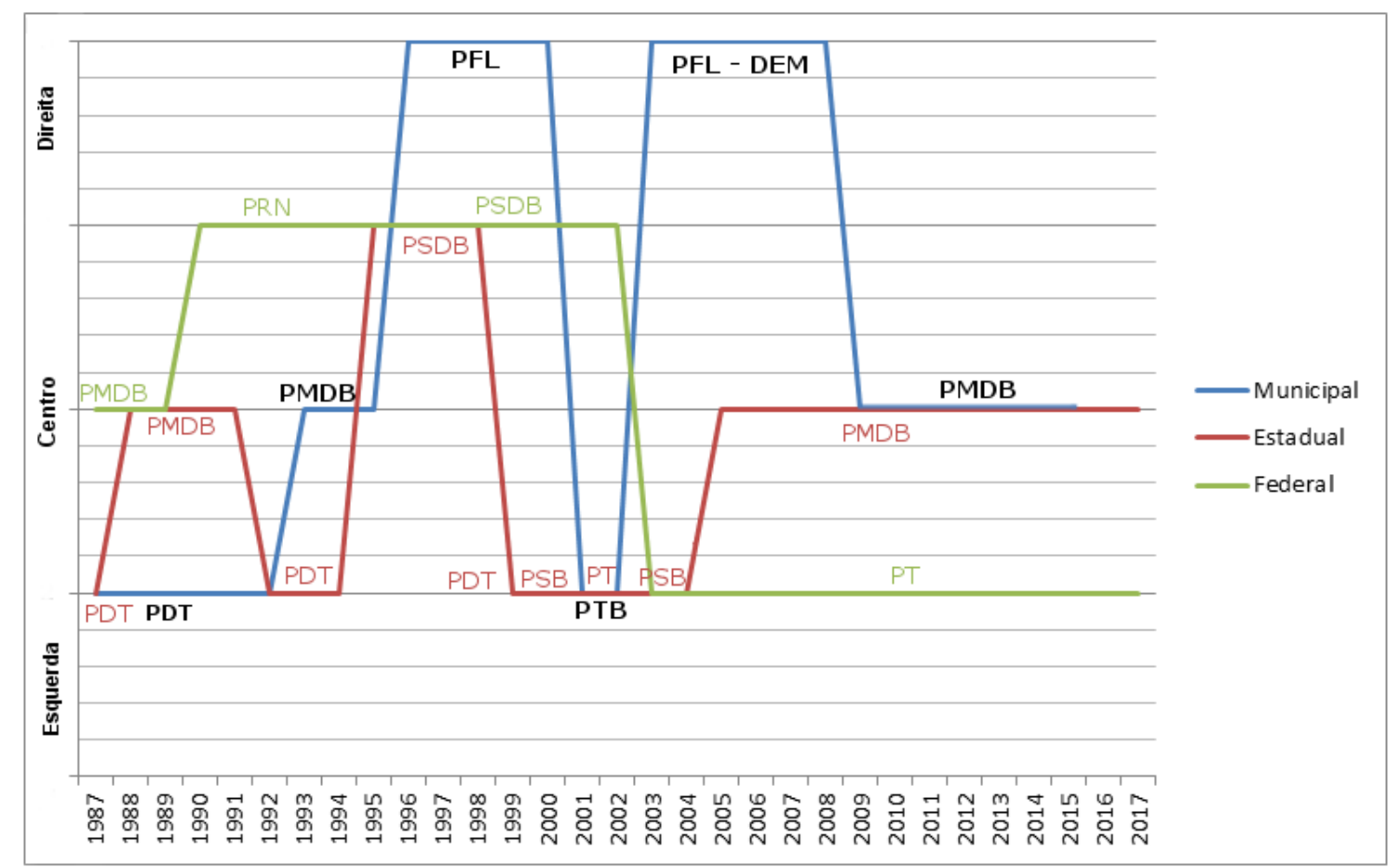

Figura 1: Histórico dos partidos nos governos municipal, estadual e federal (1987-2017). Fonte: elaboração própria do autor, 2015.

Durante os últimos anos, dada a posição partidária dos governos municipal, estadual e federal em situação, facilitou-se a obtenção de recursos e a conjunção de ações para o crescimento do Rio em diversos setores, como na coligação PMDB (municipal e estadual) e PT (federal). Contudo, durante os períodos anteriores, sobretudo nos governos de César Maia na prefeitura (1993-1996; 2001-2008) e Anthony Garotinho e Rosinha Garotinho (2000-2002; 2003-2007) no estadual, a relação entre as instâncias de poder era conflitante politicamente, levando maior morosidade e destrates. Os desentendimentos de César Maia com Rosinha Garotinho, tanto em processos eleitorais, como nas eleições municipais e estaduais e suas respectivas chapas, como nas prioridades de investimento no Rio - capital do Estado - desgastaram as relações entre o Rio e o Estado nos anos 2000.

Segundo o atual deputado federal Otávio Leite (PSDB), que foi vereador do Rio (1992-2001), deputado estadual (2002-2004) e vice-Prefeito (2005-2006) de César Maia, a relação entre a cidade e o governo estadual era conflitante em 
diversos níveis. Para ele ${ }^{3}$, durante as candidaturas às eleições municipais de 2004, o Prefeito Cesar Maia acreditaria que "a imagem de Garotinho é tão ruim no Município do Rio, que dividir palanque com ele na capital tira votos", tendo o governo estadual apoiado o ex-Prefeito Luiz Paulo Conde (PFL) que perdeu as eleições para César Maia (PTB). Segundo o próprio César Maia4, "em 2000, ele [Luiz Paulo Conde] teve esse apoio com o Garotinho com prestígio e popularidade. E perdeu. Agora, esse apoio na capital só traz desgaste. Pior para ele". Nessas eleições, no primeiro turno, ainda sem apoio de Anthony e Rosinha Garotinho, o candidato a Prefeito do Rio, Luiz Paulo Conde, teve 34,69\% dos votos contra 23,04\% de Cesar Maia. Já no segundo turno, com apoio de Anthony e Rosinha Garotinho no governo do Estado, Luiz Paulo Conde perdeu para César Maia que venceu com 1.610 .176 votos.

César Maia ainda diz: "minha opinião é que o PMDB do Rio e Garotinho entraram numa fria e apenas fizeram o jogo do competente PMDB nacional. A decisão prejudicará a todos eles no Rio, tanto o PMDB como o grupo Garotinho e ajudará o PMDB nacional". Para a vereadora Lucinha (PSDB), "hoje, o jogo está mais para o PMDB do Garotinho de um lado, e temos que formar um outro bloco do outro, com o PSDB e o PFL do Prefeito Cesar Maia"5. As trocas de partido de César Maia, migrando do PFL para o PTB para concorrer à prefeitura do Rio, bem como seu retorno ao partido e sua permanência ao longo do processo de transformação do PFL em DEM, contudo, não alterou significativamente o funcionamento da CRI, que manteve a cidade do Rio em atuação internacional. Durante seus mandatos a cidade fundou as Mercocidades, engajou-se nas disputas para sediar eventos esportivos como o Pan-Americano e defendeu a construção do Museu Guggenheim como atrativo internacional, envolvendo-se posteriormente em uma investigação e abandono do projeto e substituindo-o pela construção da Cidade da Música atualmente Cidade das Artes.

\footnotetext{
${ }^{3}$ LEITE, Otávio. César Maia desdenha apoio de Garotinho. Jornal O Dia, 21/08/2003. Disponíve em: $<<$ http://www.otavioleite.com.br/cesar-desdenha-apoio-garotinho-conde-310 > . Acesso em $26 \mathrm{de}$ mar. de 2015.

${ }^{4}$ Ibdem.

5 Ibdem. 
A relação do Rio com o governo federal também não era diferente. Dada chegada do PT ao governo federal, em 2003, as bases partidárias até 2009 também mantiveram-se em lados opostos. Apenas com a eleição de Eduardo Paes no Rio e de Sérgio Cabral para o Estado, ambos no PMDB, é que as relações partidárias com o governo federal melhoraram, garantindo maior investimento e cooperação para o desenvolvimento comum. Com as mudanças partidárias na prefeitura, em 2009, na eleição de Eduardo Paes (PMDB), que também havia integrado o governo de César Maia na Subprefeitura da Zona Oeste (1993-1997), a derrota do candidato do DEM e o apoio do governo federal (PT) e estadual (PMDB), o novo Prefeito amplia as expectativas de cooperação entre os três níveis de governo. Após duras críticas de César Maia ao candidato e novo Prefeito do Rio, em 2015 o mesmo declara6:

criei o Paes. É uma vitória. Mas se não produziu lealdade é outra história. Em 1992, ele era estagiário da vereadora Andrea Gouvêa Vieira, e me pediu para ir para assessoria jurídica da Comlurb. Mas o convenci a não ir, pois estava criando as subprefeituras, e enxergava nele um grande potencial. Ele esteve comigo na maioria dos mandatos, e só virou crítico a mim quando foi candidato a prefeito em 2008.

No governo de Eduardo Paes o cenário predominantemente de cooperação e integração de ações entre os governos municipal, estadual e federal presenciou conquistas da CRI, como a inclusão da cidade no Fórum Mundial para Cultura, na União Mundial de Cidades Olímpicas (WUOC), na Waze Connected Citzens (W10) e em sediar eventos como o Habitat 2010, Rio+20 e a Olimpíada de Verão de 2016. Nesse período diversos investimentos dos três governos possibilitaram a revitalização e grandes reformas na zona central da cidade, construindo aparelhos urbanos como o Museu do Amanhã (MAN), assinado pelo arquiteto de reconhecimento internacional, Santiago Calatrava. 0 próprio MAN insere-se em um discurso de visibilidade e conectividade com a sociedade global, uma preocupação presente na agenda política do Prefeito e, consequentemente, da CRI.

\footnotetext{
6 RESENDE, Leandro; LOPES, Eugênia. Criei o Paes. É uma vitória. Jornal o Dia, 23/11/2014. Disponível em: <http://odia.ig.com.br/noticia/rio-de-janeiro/2014-11-23/criei-o-paes-e-umavitoria-afirma-cesar-maia.html >. Acesso em: 26/03/2015.
} 
Mantendo-se ativa, a cidade do Rio manteve a CRI em diversos mandatos distintos de prefeitos e, ainda que os modelos e interesses de gestão pública pudessem se alterar, manteve-se a preocupação da cidade com sua agenda política internacional ao longo dos anos. Como visto, nos anos 1990, 2000 e 2010, o Rio manteve-se atraindo e recebendo grandes eventos internacionais, realizando acordos e tratados com outras cidades e agentes internacionais, buscando sempre atualizar sua identidade global por meio de aparelhos urbanos e sustentando na CRI uma capacidade de realização de seus interesses por meio de um corpo especializado em relações diplomáticas, ainda que paralelas ao Estado. A partir de então, após ter analisado brevemente o nível organizacional - interno e local - da paradiplomacia da cidade do Rio de Janeiro, faz-se necessário analisar essa continuidade por dados externos, em sua atuação internacional.

\section{Atuação em redes e outras instituições internacionais}

Durante o período exposto, desde sua criação em 1987 até os dias atuais, a CRI sofreu algumas alterações em sua estrutura e objetivos internacionais. A atuação externa da cidade do Rio de Janeiro manteve-se especializada em áreas tidas como estratégicas pelos governantes de forma mais coesa, sobretudo, nos anos 2000 e 2010, como no caso da cultura, esporte, inovação e superação de desafios sociais. Em sua participação na Rede de Mercocidades pode-se ver essas ações especializadas, demonstrando não um interesse em todas as áreas possíveis de atuação, mas uma escolha estratégica, ainda que em governos de partidos distintos. Por meio da coleta de dados de participação e envolvimento registrados em atas, informativos e demais documentações oficiais das Unidades Temáticas em sua totalidade, consegue-se traçar parcialmente a agenda da CRI - e da prefeitura - nas relações regionais.

A seguir expõe-se a atuação das três cidades globais presentes nas Mercocidades - Buenos Aires, Rio de Janeiro e São Paulo - desde sua fundação, em 1995, até o ano de 2014, que ainda não dispunha de toda documentação. Vale

ressaltar que a cidade de São Paulo tornou-se membro apenas em 1998 e a documentação digitalizada da rede anterior a 1999 é escassa. 


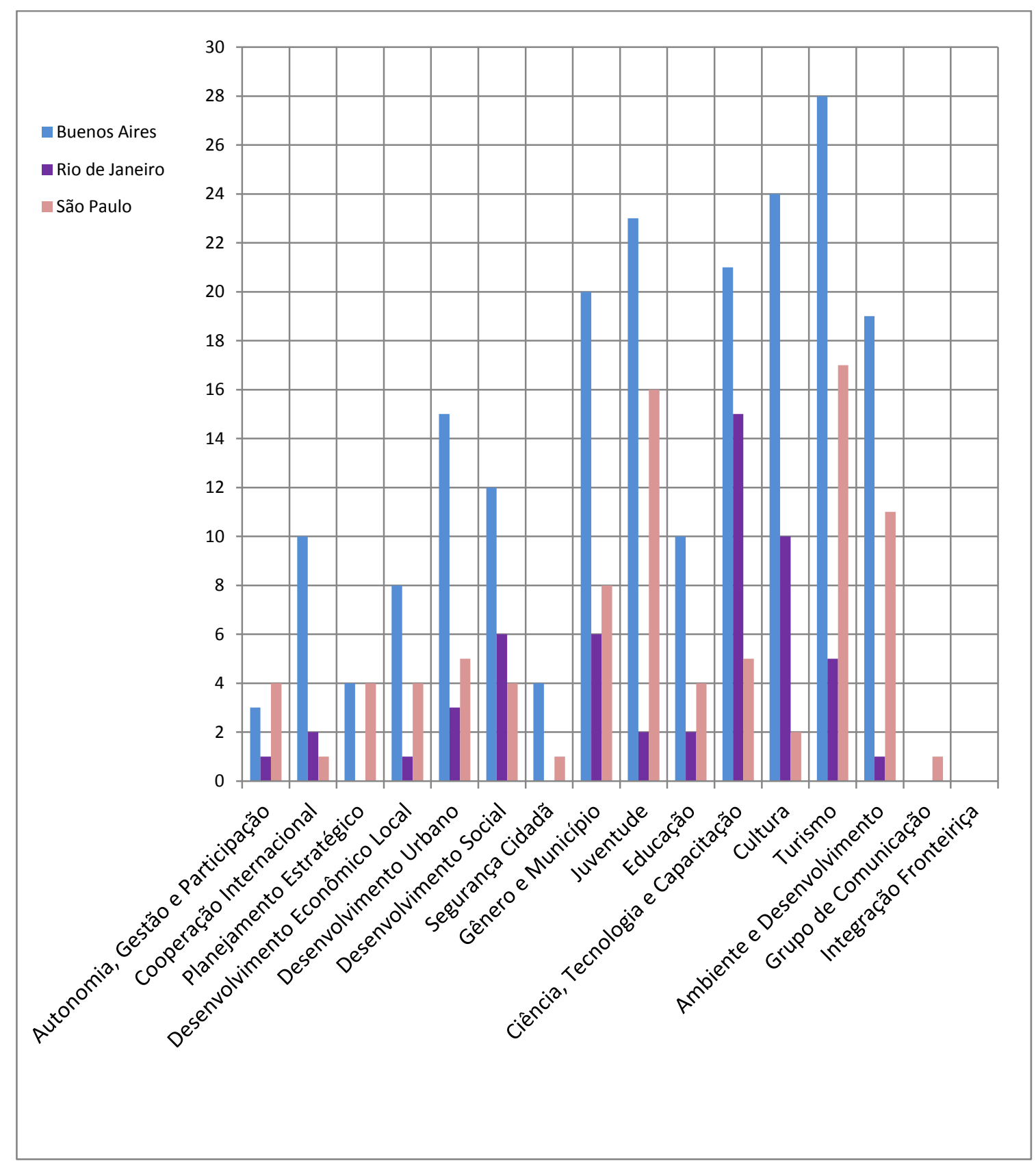

Figura 2: Participação das cidades globais nas Unidades Temáticas da Rede de Mercocidades, 19982015. Fonte: elaboração própria do autor, 2015.

De modo geral pode-se dizer que das 16 Unidades Temáticas das Mercocidades, o Rio participou ativamente de ao menos quatro: Ciência, Tecnologia e Capacitação, Cultura, Desenvolvimento Social e Gênero e Município. Essas áreas podem ser relacionadas com outros indicadores internacionais referentes à cidade, como a própria Foreign Policy, que utiliza os dados do A. T. Kearney (2008; 2010; 2012; 2014) diante de seu índice de experiência cultural e engajamento político como sendo os maiores rankings alcançados pela cidade do 
Rio. Ao observar em escala temporal, percebe-se que a cidade também manteve-se em uma constância de atuação.

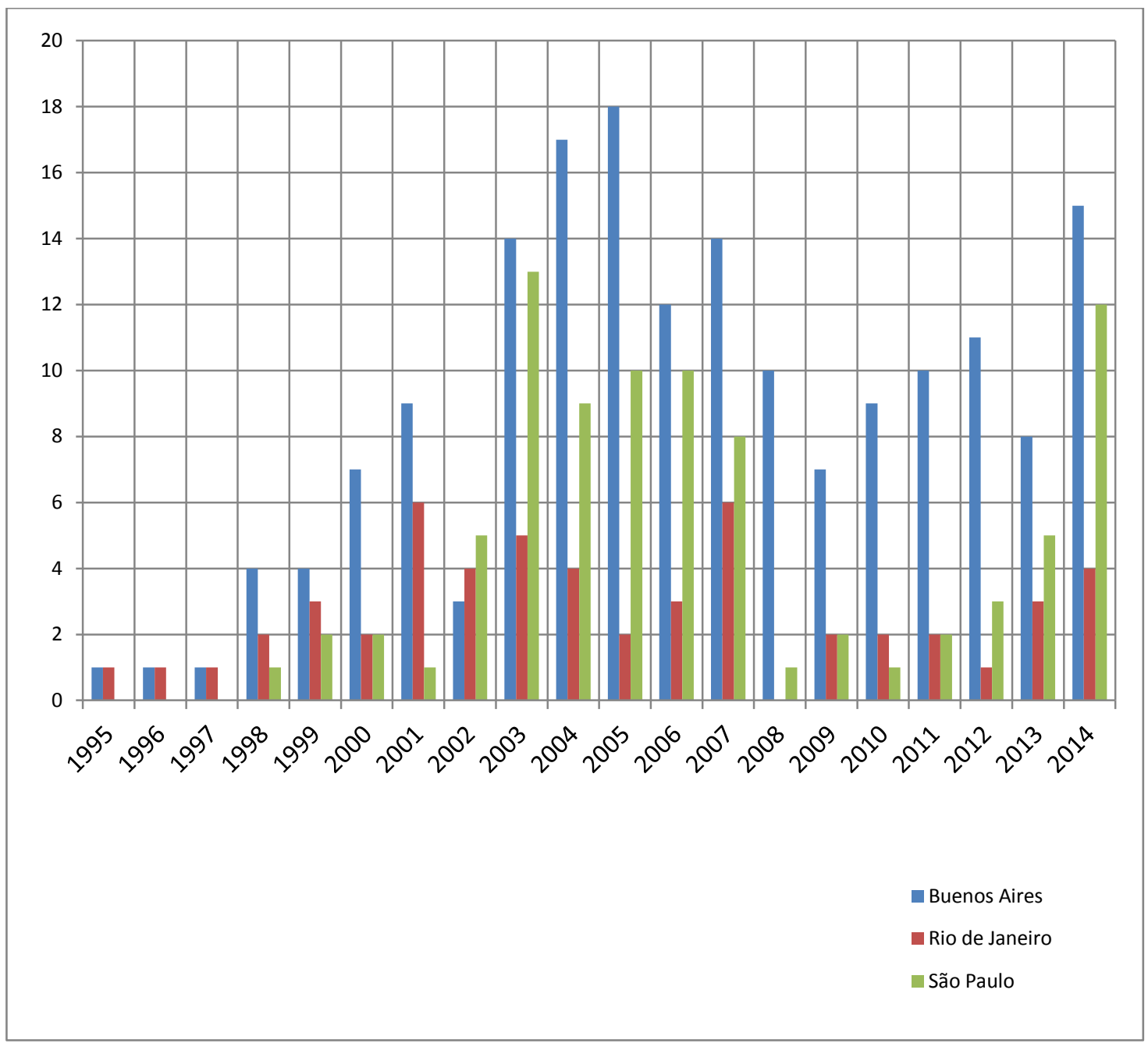

Figura 3: Participação das cidades globais na Rede de Mercocidades, 1995-2014. Fonte: elaboração própria do autor.

Diante da Figura 3 faz-se quatro ressalvas: I) os anos de 2004, 2005 e 2006 tiveram elevadas participações das cidades devido à comemoração dos dez anos de fundação; II) durante 2008 houve queda na participação das cidades brasileiras na rede, possivelmente ligada ao processo eleitoral municipal, não encontrando registros de participação da cidade do Rio de Janeiro em suas atividades documentadas; III) 2010 e 2012 foram anos em que o Rio tornou-se palco de grandes eventos internacionais, também apoiados pelas Mercocidades, diminuindo sua participação na rede para melhor gerir suas responsabilidades internacionais; IV) a participação na rede não se dá pelos membros da CRI, mas por 
representantes da prefeitura, como secretários e coordenadores; contudo, a CRI tem papel ativo na mobilização dos mesmos.

Os dados coletados das Mercocidades indicam que a cidade do Rio de Janeiro manteve-se participativa na rede, exceto durante o ano de 2008. A realização de diversos eventos internacionais na cidade, como o Encontro Internacional de Educação: Arte e Analfabetismo Funcional (2009), o Fórum Internacional de Desenvolvimento Urbano (2010) e o Congresso das Nações Unidas para o Desenvolvimento Sustentável (Rio+20, 2012). 0 projeto Mercocidades hacia Rio+20, em 2011 e 2012, tornou a cidade do Rio o centro de encontro das redes municipais regionais e internacionais de cidades, como no resultado Rio+C40, que uniu prefeitos e líderes ambientais no comprometimento de cidades em diminuírem a emissão de gases do efeito estufa, ainda que as relações entre os Estados tenham sido marcadas por dificuldades de negociação sobre o mesmo tema.

Já na criação da Rede Sul-Americana de Cidades por Bogotá, todas as cidades capitais de Estados sul-americanos foram convidadas a fazer parte, sendo exceção a essa regra as cidades de São Paulo e Rio de Janeiro, que também foram chamadas a integrar a organização devido à sua importância regional. Já em âmbito mais global, a participação da cidade do Rio na Agenda 21 para Cultura das Cidades e Governos Locais Unidos (CGLU) é reconhecida como fundamental, tornando-se parte do mapa alegórico dos agentes que possibilitam uma maior responsabilidade internacional com a cultura (Figura 4) e em sua participação, em 2014, no novo debate para reformulação do mesmo documento e no Grupo de Trabalho Cultural da CGLU realizado na cidade de Buenos Aires, juntamente com outras redes, como a Mercocidades. 




Figura 4: Detalhe do Mapa Alegórico da Agenda 21 para Cultura representando os agentes internacionais em escala de importância como vias de ações culturas no mundo. Fonte: Circular 28, Comissão de Cultura (CGLU, 2009).

Sua relação com a UN-Habitat, UNESCO e Banco Mundial do Sistema ONU também colaboram no reconhecimento da cidade como um agente importante no cenário internacional de ação subnacional. Desde o reconhecimento como patrimônio paisagístico natural e humano pela UNESCO, do empréstimo de 1,9 bilhão de dólares pelo Banco Mundial e da realização de eventos internacionais, como a EC092, passando pelo Fórum de Desenvolvimento Urbano (UN-Habitat em 2010) e os diversos eventos esportivos que a tornou membro das Cidades Olímpicas, ampliam a atuação do Rio para além das redes e a insere em um complexo cenário de relações. Durante o período de atividade da CRI (1987-2015) não foi possível perceber um abandono significativo em nenhum momento por parte da cidade do Rio de Janeiro em relação às dinâmicas internacionais. 


\section{Considerações Finais}

Mesmo com alternância partidária, as ações da CRI mantiveram-se ativas. Isso, possivelmente, ao fato da cidade manter uma preocupação com sua participação política internacional para além de períodos partidários no poder. Diversas questões surgem diante dessa problemática para explicar a continuidade, como comunidades epistêmicas, relações não-partidárias e compartilhamento de valores dos gestores públicos. Contudo, isso exige um trabalho mais amplo a ser desenvolvido. Por hora os resultados do presente trabalho confirmam a existência de uma participação da cidade em dinâmicas internacionais mesmo em períodos partidários distintos. Algumas áreas específicas, como a cultural, esportiva, técnico-científica e de desenvolvimento urbano e social mantém-se como as principais zonas de atuação nas redes internacionais, juntamente com outros agentes do Sistema ONU.

Em relação às ações autônomas, o Rio tornou-se cidade-irmã e parceira de muitas outras, bem como trouxe para si visibilidade na realização de eventos internacionais. Por conseguinte, a CRI teve papel fundamental na organização dessas dinâmicas como parte institucional do poder executivo - prefeitura - de 1987 até 2015, data presente da pesquisa. Se desafios surgiram para o Rio durante períodos de oposição partidária entre os três níveis - municipal, estadual e federal, os mesmos não levaram a um abandono da política internacional na agenda da cidade. Ao contrário, foi possível perceber, inclusive, um incremento maior da cidade em períodos de desentendimentos na busca de capital externo, investindo na imagem da cidade diante da comunidade internacional por meios diversos.

Novos estudos devem ser feitos para aprofundar as questões aqui levantadas, mas já com uma resposta. Pode-se dizer que a cidade do Rio de Janeiro possui uma agenda de política internacional? Sim e sua atuação não é pontual, mas contínua de preocupação com as relações internacionais. E isso pôde ser visto na criação e funcionamento da CRI. É difícil identificar forte relação entre alterações partidárias e a continuidade da CRI, exigindo investigações mais pontuais como nos vínculos pessoais entre os gestores, demandas internacionais de atuação e 
comunidades epistêmicas que orientam a gestão e atuação internacional de agentes subnacionais.

A análise constata que toda essa atividade exige uma coordenação da prefeitura. Essa coordenação materializa-se na CRI, mas também denota que a cidade possui, de fato, uma paradiplomacia, isto é, possui agendas políticas internacionais ao longo dos mandatos dos prefeitos com interesses próprios que vão além da agenda nacional ou mera atuação pontual, como ocorre com outros governos subnacionais no Brasil. A cidade do Rio, como maior fluxo turístico internacional do país, preocupa-se com sua identidade por meio das práticas, assim como preocupa-se em captar recursos estrangeiros e fortalecer instituições de ação subnacional nas relações internacionais. Cabe à CRI materializar estratégias para maior e melhor alcance dos interesses municipais nas dinâmicas internacionais contemporâneas - algo que já vem fazendo por quase três décadas.

\section{REFERÊNCIAS}

A.T. Kearney Global Management Consultants; The Chicago Council of Global Affairs; SASSEN, Saskia. The 2008 Global Cities Index. Washington: Foreign Policy Magazine, pp. 68-76, nov./dez. 2008.

CGLU, Cidades e Governos Locais Unidos. Circular 28 da Comissão de Cultura, 2009. Disponível em $<$ http://www.agenda21culture.net/index.php/documents/reports $>>$. Acesso em 20/03/2015.

CRI, Coordenadoria de Relações Internacionais da Prefeitura do Rio de Janeiro. Estrutura, histórico, informativos e demais documentos oficiais. Disponível em: $<<$ http://www.rio.ri.gov.br/web/relacoesinternacionais/a-coordenadoria >>. Acesso em 05/04/2015.

FRIEDMANN, John. The World City Hypothesis. In. Development and Change. Londres: Sage Publication vol. 17, 1986, pp. 69-83.

GAWC, Globalization and World Cities Research Network. Departamento de Georgrafia da Universidade de Loughborough. Disponível em $<$ http://www.lboro.ac.uk/gawc/cities.html >. Acessado em 04/04/2015.

GLOBAL CITIES INSTITUT, THE. Universidade de Toronto. Disponível em $<$ http://www.globalcitiesinstitute.org $>$. Acesso em 04/04/2015. 
MERCOCIDADES. Estrutura, Unidades Temáticas, atas, informativos e demais documentos oficiais. Disponível em: $<<$ http://www.mercociudades.org/pt-br $>>$. Acesso em 04/04/2015.

ROSENAU, James. Turbulence in world politics. Nova Jersey: Princeton University Press, 1990.

SASSEN, Saskia. The Global City: New York, London, Tokyo. Nova Jersey: Princeton University Press, 1991.

SASSEN, Saskia. Sociologia da globalização. Porto Alegre: Artmed, 2010.

WENDT, Alexander. Social Theory of International Politics. Cambridge: Cambridge University Press, 1999. 